\title{
Implicações e impasses do Programa de Erradicação do Trabalho Infantil (PETI) no semiárido baiano (1997-2008)
}

\begin{abstract}
Aline dos Santos Lima ${ }^{1}$
RESUMO: O trabalho infanto-juvenil por muito tempo foi considerado uma prática natural. Nas últimas décadas do século XX, essa cultura começou a ser coibida, devido à atuação de uma rede - composta por organismos internacionais, Estado e sociedade civil - que qualificava o trabalho como prejudicial, nesse período da vida, por afastar as crianças e os adolescentes da escola e impedir o desenvolvimento físico e psicossocial. No Brasil, uma das medidas dessa "nova” visão foi à criação do Programa de Erradicação do Trabalho Infantil (PETI). Essa política pública propunha combater o trabalho infanto-juvenil, encaminhando as crianças e os adolescentes à escola em tempo integral, mediante um auxílio financeiro mensal e a inserção das famílias em atividades de geração de emprego e renda. Na Bahia, o PETI foi implantado, pioneiramente, no município de Retirolândia, localizado no atual Território do Sisal, o qual concentrava umas das piores formas de trabalho infantil na cadeia produtiva do agave sisalana (sisal). Propomos analisar o que esse Programa construiu em mais de uma década de existência, indicando suas implicações e limites.
\end{abstract}

PALAVRAS-CHAVE: Trabalho infantil, política pública, PETI, território do Sisal, participação.

ABSTRACT: Child labour was considered to be natural for a long time in Brazil. During the last decades of the $20^{\text {th }}$ century, these ideas started to be controlled by a network, composed of international organizations', the State and civil society. These groups classified child labour as damaging, because it distanced the children from school, as well as impeding their physical and psycho-social development. In Brazil, one of the measures of this "new" vision was the creation of the Programme for the Erradication of Child Labour (PETI). This public policy proposed to combat child labour by placing the children and teenagers in full-time school, and giving financial assistance to the families or some kind of income-providing activity. In Bahia, the first project was implanted in Retirolândia, localized in the Sisal Territory, where the worst forms of child labour were concentrated in the production of agave sisalana (sisal). ${ }^{2}$ Our intention with this study is to assess what the Programme has achieved over the decade of its existence, as its implications and limits.

KEYWORDS: Child labour, public policies, PETI, Sisal territory, participation.

\footnotetext{
${ }^{1}$ Licenciada em Geografia pela Universidade do Estado da Bahia. Mestre em Cultura, Memória e Desenvolvimento Regional pela UNEB. E-mail: lineuneb@yahoo.com.br

${ }^{2}$ Fleshy, spiny plant used in rope-making.
} 


\section{Desfibrando o trabalho infantil}

O trabalho infanto-juvenil por muito tempo não era visto como problema a ser combatido. A utilização dessa mão-de-obra era tida com naturalidade, como parte do processo de socialização das crianças. Dentre os diversos motivos que disseminaram o trabalho de crianças e adolescentes, salientamos dois aspectos. O primeiro é o de que contratar esses indivíduos é “mais barato” que os adultos, além de ser uma mão-de-obra que não busca se organizar para obter proteção e apoio. O segundo refere-se à necessidade doméstica, uma vez que, em muitos casos, a renda auferida é insuficiente para garantir o sustento, tornando imprescindível a participação do maior número de membros da família, até mesmo daqueles em idade escolar.

É válido acrescentar que conceituar trabalho infantil não é uma tarefa simples como pode parecer. A priori, é necessário ter em mente como é estabelecida a noção de infância, já que esta designa os limites do "ser” criança ou adulto. A infância pode ser definida tanto em função da idade, quanto pelo cumprimento de ritos sociais e obrigações tradicionais.

Segundo Ariès (1981), nas sociedades tradicionais do Ocidente, o sentimento de infância inexistia durante a Idade Média, período em que a criança era vista como um adulto em miniatura. O autor afirma que, no século XII, a iconografia medieval desconhecia a infância ou não tentava representá-la, e até o início do século XVII os trajes, os jogos e as brincadeiras não distinguiam os adultos das crianças. A maioria dos brinquedos, por exemplo, eram representações do mundo adulto, como o cavalo de pau, o cata-vento e as bonecas. Eles foram criados com o intuito de emular as crianças, levando-as a imitar as atitudes dos mais velhos, através da redução à sua escala.

Assim, a infância era limitada a um curto período e durava apenas enquanto a criança não sabia viver sem os cuidados maternos, recebendo da mãe a atenção e o acompanhamento, fase chamada de "paparicação”. A partir do momento em que a criança conseguia se bastar e adquirir desembaraço físico, ou melhor, até quando conseguia superar os primeiros perigos e sobreviver ao tempo da "paparicação”, eram misturadas aos adultos, partilhando dos jogos de azar, do divertimento nas tavernas, presenciando e sendo envolvidas nas brincadeiras sexuais.

Para Ariès (1981), os primeiros elementos que distinguem o mundo da criança e dos adultos começam a surgir no século XIV, mas essa separação se dá em diversos graus entre 
os grupos sociais. Nas camadas mais pobres da população, permaneceu a indeterminação entre adultos e crianças, prevalecendo as mesmas brincadeiras, os jogos, os trajes e as experiências do mundo do trabalho.

Nessa perspectiva, o trabalho infanto-juvenil foi naturalizado como parte da formação individual e considerado solução para o problema do infante abandonado e desvalido, bem como instrumento para prevenir a criminalidade ao preparar a mão-de-obra para a agricultura e indústria. Segundo Thompson (1987, p. 203), com base nos relatórios das “Comissões sobre o Emprego das Crianças”, em 1842, as crianças indigentes de seis, sete ou oito anos, eram submetidas ao trabalho como aprendizes. Nas mãos dos capatazes ou de operários, muitas vezes, eram vítimas de maus-tratos, de jornadas intensas e desgastantes, pois a “criança era uma parte intrínseca da economia industrial e agrícola antes de 1780, e como tal permaneceu até ser resgatada pela escola”.

No Brasil, durante as primeiras décadas do século XX, era comum os filhos das famílias menos abastadas ingressarem na condição de aprendizes nas instituições preparatórias de mão-de-obra para o mercado de trabalho. Asilos de caridades foram transformados em institutos, escolas profissionais e patronatos agrícolas para formar a mão-de-obra necessária aos setores agrícolas e industriais, conforme apontam Leal (1996) e Rizzini (2002).

Segundo Antuniassi (1983), após a Segunda Guerra Mundial, os temas relacionados à infância passaram a fazer parte dos programas de desenvolvimento em países considerados centrais. Consequentemente, o público infanto-juvenil passou a ser visto como um ser em formação, e o trabalho, enquanto responsabilidade inerente ao mundo adulto, impediria o pleno desenvolvimento físico e psicossocial. Por esse viés, a ideologia dominante estabeleceu um limite abaixo do qual o trabalho infantil deveria ser eliminado. Entretanto, essa mudança paradigmática se espalhou com diferentes perspectivas e intensidade entre os países.

A emergência da proteção às crianças e aos adolescentes no Brasil desponta em meados da década de 1980, com mais ênfase nos anos 1990. Desse modo, a legislação em favor da proteção das crianças e dos adolescentes, que até então fora negligenciada, veio à tona. O contexto de redemocratização, a partir do final de 1980, favoreceu a articulação entre organismos internacionais, Estado e sociedade civil, em prol de experiências em defesa dos direitos da infância. 
A Constituição Federal de 1988 criou a obrigatoriedade na proteção dos direitos das crianças, posteriormente regulamentados com a aprovação do Estatuto da Criança e do Adolescente (ECA) em 1990. Atreladas a isto, vieram à baila inúmeras denúncias de trabalho infanto-juvenil divulgadas pela mídia, levando o tema a fazer parte da agenda nacional de políticas sociais através de uma intensa mobilização para afastar as crianças do mercado de trabalho. Segundo o Ministério do Desenvolvimento Social e Combate à Fome (MDS) (2004a), o país apresentou, em 1980, cerca de 6,9 milhões de crianças e de adolescentes trabalhando e em 1992 esse número saltou para 9,6 milhões, indício de que as proposições legais não estavam sendo cumpridas.

Para coibir essa prática, em 1996, o Governo Federal, através do Ministério da Previdência e Assistência Social (MPAS), criou o Programa de Erradicação do Trabalho Infantil (PETI). O Programa, de acordo com o MPAS (199-, p. 8), era destinado “às famílias com filhos na faixa etária entre 7 e 14 anos, submetidos a trabalhos caracterizados como insalubres, degradantes, penosos e de exploração infantil na zona rural”. Mediante auxílio financeiro, Bolsa Criança Cidadã, a família deveria tirar os filhos do trabalho, encaminhálos à escola regular e, em turno oposto, às atividades socioeducativas também chamadas de Jornada Ampliada.

Antes de o PETI ser implantado, o Ministério do Trabalho e Emprego (MTE) criou um grupo interdisciplinar para mapear as áreas com focos nas piores formas de trabalho infanto-juvenil. Os grupos especiais identificaram a incidência dessa mão-de-obra em atividades consideradas penosas no Mato Grosso do Sul, em Pernambuco e na Bahia, respectivamente, na exploração de carvão, cana-de-açúcar e sisal.

Na Bahia, o PETI foi implantado inicialmente no semiárido produtor do sisal, ou agave sisalana. A rede produtiva desse vegetal - iniciada no campo e prolongada até os sítios urbanos - concentrava um elevado número de crianças e adolescentes, situação que elegeu a antiga Região Sisaleira como a pioneira do movimento pró-erradicação do trabalho infantil no estado. Desse modo, através da Portaria n. 230 de 12 de julho de 1996, foi criada a Comissão Estadual de Prevenção e Erradicação do Trabalho Infantil (COMPETI) presidida e coordenada pela antiga Secretaria do Trabalho e Ação Social (SETRAS). Essa Comissão era composta por instituições governamentais e não governamentais que se articulavam com subcomissões regionais (presentes nas Regiões Econômicas Nordeste, 
Paraguaçu e Piemonte da Diamantina, que integravam alguns municípios que compunham a antiga Região Sisaleira) e municipais.

A primeira atribuição da COMPETI foi definir os municípios percussores do PETI no estado. No segundo semestre de 1997, após uma série de visitas à antiga Região Sisaleira, ${ }^{3}$ foram escolhidos cinco municípios do semiárido que possuíam as piores formas de trabalho executadas por crianças e adolescentes: Retirolândia, Santaluz, Conceição do Coité, Riachão do Jacuípe e Valente.

Retirolândia sobressaia por congregar simultaneamente o maior nível de organização e mobilização social, elevado contingente de mão-de-obra infantil e alto índice de pobreza. Além disso, esse município atraía a atenção dos organismos internacionais ligados à questão do trabalho mesmo antes do PETI. Não obstante os baixos indicadores sociais, as entidades locais desse município se empenharam em defesa das famílias carentes das zonas rurais e periferia urbana. Nessa linha, o Sindicato dos Trabalhadores Rurais (STR) se comprometeu a resguardar os direitos dos seus associados, como a luta em prol da aposentadoria dos mutilados do sisal e a erradicação do trabalho de crianças e adolescentes.

A atuação do Sindicato retirolandense pode ser apreciada através de um Projeto considerado inovador para a região - projeto desenvolvido pelo mesmo com o apoio da Organização Internacional do Trabalho (OIT) e do Movimento de Organização Comunitária $^{4}$ (MOC) -, chamado Bode Escola, em 1995/96. Inspirado nas práticas de fundos rotativos e bancos de sementes, o Bode Escola previa, inicialmente, a seleção/identificação de famílias que possuíam crianças trabalhando. Estas eram selecionadas pelo STR e recebiam como “empréstimo” quatro cabras e um bode, com a proposta de melhorar a condição alimentar e formar um pequeno rebanho para complementar a renda. Em contrapartida, a família se responsabilizava por tirar as crianças

\footnotetext{
${ }^{3}$ Recorte espacial atribuído à área semi-árida produtora de agave sisalana ou sisal - vegetal implantado pelo governo do estado a partir de 1930, como forma de fixar a população com uma fonte de renda. Em setembro de 2003, essa área passou a ser tratada, oficialmente, como Território do Sisal - recorte adotado pelo Estado, com base na abordagem territorial desenvolvida pelo Ministério do Desenvolvimento Agrário e Secretaria do Desenvolvimento Territorial - e abarca 20 municípios.

${ }^{4}$ Entidade criada em 1967, sob orientação da Cáritas Brasileira - órgão assistencial fundado em 1956 pela Conferência Nacional dos Bispos do Brasil. Atualmente, o MOC desenvolve programas em 36 municípios que integram os Territórios do Sisal, Bacia do Jacuípe, Piemonte da Diamantina e Portal do Sertão, no estado da Bahia. Com a missão de contribuir para o desenvolvimento integral, participativo e ecologicamente sustentável da sociedade humana, a entidade atua através de sete programas, desenvolvendo ações nas áreas de comunicação, educação do campo, agricultura familiar, recursos hídricos, gênero, criança e adolescente e políticas públicas.
} 
e adolescentes do trabalho e, ao final do ano, entregar a metade do rebanho ao Sindicato, como garantia de continuidade do projeto.

\section{O Programa de Erradicação do Trabalho Infantil em Retirolândia (BA)}

O PETI é uma política pública, ou seja, constitui uma articulação de ações reguladas e providas pelo Estado mediante a pressão da sociedade (ARAÚJO, 2000; ARRETCHE, 2000; 2006). Portanto, sua criação pressupõe uma gestão descentralizada e participativa, características derivadas das mudanças introduzidas pela Constituição Federal de 1988, abertura que favoreceu a articulação do Estado e da sociedade civil com a rede de organismos internacionais que defendiam experiências em defesa dos direitos da infância.

Nos primeiros anos de existências o PETI ampliou o público-alvo - incorporando as famílias da zona urbana - e aumentou o período de permanência - estendendo aos 15 anos a idade limite. Desse modo, de acordo MPAS (2002, p. 2), o Programa passou a ter como objetivo geral a retirada de "crianças e adolescentes de sete a 15 anos de idade do trabalho considerado perigoso, penoso, insalubre ou degradante, ou seja, daquele trabalho que coloca em risco sua saúde e sua segurança”.

Além disso, segundo o MPAS (2002, p. 2) e MDS (2004c, p. 3), o PETI tinha objetivos específicos centrados no não trabalho, na escolarização e na família, como:

a) retirar crianças e adolescentes do trabalho perigoso, penoso, insalubre e degradante;

b) possibilitar o acesso, a permanência e o bom desempenho de crianças e adolescentes na escola;

c) fomentar e incentivar a ampliação de conhecimentos da criança e do adolescente, por meio de atividades culturais, esportivas, artísticas e de lazer no período complementar ao da escola, ou seja, na Jornada Ampliada;

d) proporcionar apoio e orientação às famílias por meio da oferta de ações socioeducativas; e

e) promover e implementar programas e projetos de geração de trabalho e renda para as famílias. 


\section{O PETI como ele deveria ser}

O PETI se constituiu como um programa articulado em duas ações: o serviço socioeducativo e a concessão da Bolsa Criança Cidadã. A família beneficiada recebia uma bolsa mensal para cada filho retirado do trabalho. Em contrapartida, as crianças e os adolescentes deveriam frequentar a escola regular e, em turno oposto, participar de atividades esportivas, culturais, artísticas, de lazer e de reforço escolar, chamadas de Jornada Ampliada.

Essas atividades eram propostas pelos monitores: profissionais que, após processo de capacitação, se tornavam os responsáveis pela execução das diversas ações desenvolvidas na jornada. A capacitação previa uma instrução mínima aos educadores com o objetivo de subsidiar a construção de uma proposta pedagógica diferenciada - exigência que não correspondia à realidade dos educadores de algumas localidades, sobretudo, pela falta de formação e consciência do papel de mediador no processo educativo.

A jornada deveria acontecer em espaços com condições de atender o número de crianças e adolescentes beneficiados, denominados como Unidades de Jornada Ampliada (UJAs). Esses espaços precisavam dispor de instalações apropriadas para refeições, estudos, recreação ao ar livre, dinâmicas de grupo, atividades artísticas, culturais e desportivas devendo ainda apresentar boa iluminação, ventilação, condições higiênicas e sanitárias adequadas e equipadas com cadeiras, mesas e armários. Para tanto, poderiam ser aproveitadas instalações já existentes desde que adaptadas ou ainda construir espaços próprios, conforme indicações do MPAS (2002) e MDS (2004c).

Ao longo dos anos, o PETI passou por mudanças. Atualmente, o programa está alocado no MDS através da Secretaria Nacional de Assistência Social que responde, dentre outros, pelo Departamento de Proteção Social Básica e de Proteção Social Especial. A primeira é destinada à prevenção de situações de risco pessoal e social e ao fortalecimento e desenvolvimento de potencialidades das famílias e dos indivíduos. A segunda é voltada para a proteção de famílias e indivíduos em situação de risco social e pessoal, abarcando aquelas inseridas no PETI.

O PETI mantém o serviço socioeducativo e a transferência de renda. O objetivo inicial de contribuir para a erradicação de todas as formas de trabalho infantil prevalece com 
modificações, como a extensão do tempo limite de permanência - passando a atender crianças e adolescentes com idade inferior a 16 anos.

Outra mudança, quiçá de maior repercussão, é a integração do PETI ao Programa Bolsa Família (PBF). O PBF, criado pela Lei 10.836 de 9 de janeiro de 2004 e regulamentado pelo Decreto 5.209 de 17 de setembro de 2004, é um programa de transferência direta de renda, com contrapartidas, ou melhor, condicionalidades, que beneficia famílias em situação de pobreza ou extrema pobreza. A junção PETI/PBF é disciplinada pela Portaria N. ${ }^{\circ} 666$ de 28 de dezembro de 2005. Esta, através do artigo décimo segundo, determinava que as prefeituras eram obrigadas a inserir as informações relativas a cada família em situação de trabalho infantil no Cadastro Único para Programas Sociais para o Governo Federal (CadÚnico), obrigatoriamente, até 31 de março de 2006.

Com as mudanças, as famílias em situação de pobreza e extrema pobreza passavam a integrar o PBF e por extensão os filhos menores em situação de trabalho deveriam ser encaminhados às ações socioeducativas e de convivência do PETI. Tal medida contemplava um dos objetivos da integração PETI/PBF: ampliar a cobertura do atendimento às crianças ou adolescentes trabalhadores.

\section{O PETI como ele é}

A Região Sisaleira na década de 1990 era marcada por condições socioeconômicas precárias. A fragilidade de sua base produtiva, a crise da lavoura sisaleira, as limitadas alternativas de subsistência, as longas estiagens, o mandonismo do poder local e a presença marcante do trabalho infantil eram prementes. É nesse cenário que o Estado constitucional de direito emerge para alterar aquela antiga condição forjada ao longo dos anos, e o PETI é uma das vias dessa mudança.

As primeiras dificuldades surgem antes mesmo de o Programa começar. A COMPETI organizou um encontro, no final de 1996, com a participação de representantes do governo do Estado, gestores municipais e membros de organizações não governamentais para dispor as bases do processo de cadastramento e a seleção das famílias a serem beneficiárias, o que resultou no convênio SETRAS/Centro de Recursos Humanos da Universidade Federal da Bahia (CRH-UFBA). 
A etapa do cadastramento, assumida pelo CRH-UFBA, visava à identificação das famílias com filhos entre 0 a 14 anos, que residiam na zona rural e/ou periferia urbana, concreta ou potencialmente envolvidas em atividades produtivas perigosas, como o trabalho com o sisal. Além disso, objetivava o levantamento de informações sobre as condições sociais, econômicas e culturais e a capacidade de oferta de serviços básicos de atendimento social, sobretudo educação e saúde, estudo que ficou conhecido como Pesquisa Criança Cidadã, conforme Ramos e Almeida (1997).

Após o cadastramento das famílias, partiu-se para uma decisão complexa: definir aquelas que seriam contempladas com o programa. A seleção foi feita com base na elegibilidade de critérios previamente estabelecidos - metodologia que incomodou algumas entidades locais que já dispunham de listas prontas com supostas famílias carentes.

A Pesquisa Criança Cidadã identificou em Retirolândia 1.589 domicílios na área rural compreendendo, 7.468 indivíduos. Desse universo, 1.759 (23,6\%) eram crianças e adolescentes na faixa etária de 7 a 14 anos, sendo 51,1\% do sexo masculino e 48,9\% do sexo feminino. Do total de crianças e adolescentes em idade escolar, 95,4\% estudavam em 1996. Dentre estes, 82,6\% estavam entre o pré-escolar e a $3^{\circ}$ série do Ensino Fundamental e 57,1\% trabalhavam e estudavam ao mesmo tempo - indícios da defasagem idade-série.

As condições educacionais do município também foram abordadas. Foi apontado que as 32 escolas e as 3 creches, no geral, apresentavam necessidades que iam da requisição de construir salas de aula, cantinas, sanitários, até a falta de equipamentos para o armazenamento e preparo da merenda, armários, bebedouros, sem contar a natureza multisseriada das classes e a falta de qualificação dos professores, como apontam Ramos e Almeida (1997).

Antes de salientarmos os benefícios e os limites do PETI é mister esclarecermos o processo de construção da nossa pesquisa. Buscamos analisar as implicações causadas pelo PETI após mais de uma década de existência, bem como quais dos seus objetivos foram realmente atingidos. Após o levantamento bibliográfico, a consulta do tema em jornais e revistas, a visita nas entidades e secretarias responsáveis pela execução do Programa, partimos para a coleta de dados primários.

Para construirmos nossa base de dados com informações primárias adotamos a técnica do grupo focal com grupos de atuais beneficiários do PETI. Essa técnica, proposta pelo 
sociólogo Robert King Merton apud Gomes (2005), consiste em obter informações sobre determinados aspectos vivenciados por grupos de indivíduos. O primeiro grupo focal aconteceu com estudantes do Ensino Fundamental da Escola Municipal Valdeci Lobão, atuais beneficiários do PETI. Essa unidade escolar, segundo a Secretaria de Assistência Social de Retirolândia, é a que concentra o maior número de alunos integrados ao programa na rede pública municipal. Dos 585 alunos regularmente matriculados em 2008, 43,7\% são beneficiários. O segundo ocorreu com estudantes do Ensino Médio do Colégio Estadual Olavo Alves Pinto, que saíram ou estão prestes a sair do programa por terem atingido a idade máxima de permanência.

Os grupos focais permitiram que conhecêssemos o PETI através daqueles que estão no programa ou que o deixaram recentemente. Essa atividade deu subsídio para a construção de questionários, que foram aplicados posteriormente aos egressos, aos professoresmonitores e aos coordenadores.

A identificação dos egressos, para aplicação dos questionários, tomou como base uma relação dos cadastrados elaboradas pela Pesquisa Criança Cidadã, feita em 1997, pelo CRH-UFBA. Entretanto, existe uma incompatibilidade entre o número divulgado oficialmente no relatório da pesquisa (1.759 crianças e adolescentes) e a listagem disponibilizada. Esta última indica que existiam 1.520 cadastros. Como a listagem aponta o nome completo e o local de residência dos registrados, optamos por adotá-la como referência na aplicação dos questionários.

Entre os 1.520 indivíduos, na época crianças e adolescentes que tinham entre 7 a 14 anos, selecionamos 306. A definição da quantidade e a seleção dos egressos basearam-se em Gerardi e Silva (1981). Essas autoras, versando sobre os procedimentos matemáticoestatísticos aplicados na Geografia, sugerem estratégias para o levantamento de informações e de noções gerais sobre a seleção de amostragem em unidades espaciais e não espaciais.

No caso da nossa pesquisa, que prioriza a dimensão não espacial, determinamos a amostra a partir do tamanho da população. Em um universo que vai de 1.500 até 1.599 indivíduos, segundo Krejcie e Morgan apud Gerardi e Silva (1981), o número de amostras deve ser 306. Colocamos os 1.520 cadastrados em ordem alfabética e adotamos como intervalo para a escolha de cada um dos 306 egressos a seleção sistemática. Esta, ainda de acordo com as 
autoras, consiste na "retirada” da amostra mediante a divisão do número total de elementos da população pelo número de elementos que desejamos retirar. No caso da nossa pesquisa, o intervalo de retirada da amostra foi de 1 a cada 5 nomes.

A meta era encontrar 306 indivíduos, no universo de 1.520 cadastrados, aplicarmos os questionários e analisarmos as mudanças ocorridas nas suas trajetórias de vida. Dos 306 selecionados, identificamos 215; não tentamos localizar os demais, pois as respostas estavam repetitivas e, então, resolvemos mensurar os dados já adquiridos. Entre os 215 egressos identificados, aplicamos o questionário para 99, tendo em vista que 81 não residem mais no município. A maior parte, segundo os familiares e amigos mais próximos, partiu em busca de emprego e melhores condições de vida. Dos 35 restantes, 16 não deram retorno, 8 foram cadastrados e não participaram do Programa, 7 não quiseram responder, 3 não foram reconhecidos nas comunidades e 1 está detido.

Parte dos egressos foi categórica na recusa em participar. Outros procuraram os seus antigos professores-monitores para consultá-los sobre as perguntas e sobre possíveis implicações de suas respostas. Alguns, entretanto, foram muito solícitos, nos indicaram parentes dos ex-colegas e nos orientaram sobre o paradeiro dos que migraram. O mesmo aconteceu com os participantes dos grupos focais e alguns professores-monitores.

Entre os monitores, a recusa se repetiu. Em Retirolândia, no ano de 2008, existiam 37 educadores no PETI, sendo que 3 exerciam atividades de coordenação. Solicitamos, durante uma reunião de planejamento, que os 34 que atuavam na sala de aula respondessem a um questionário específico. Porém, apenas 50\% retornaram. Fomos informados de que alguns recearam responder “certas” questões. Cabe atentar para o fato de que 2008 foi um ano eleitoral. As eleições municipais influenciaram nos ânimos da população no período pré e pós-eleitoral. Imaginamos que esse motivo tenha provocado algumas rejeições em responder aos questionários, tanto entre os professores-monitores quanto entre os egressos.

Além disso, surgiram outras dificuldades no desenrolar da pesquisa. A coordenação do PETI no município não dispõe de dados sistematizados sobre o programa, todas as informações geradas eram/são passadas às secretarias estaduais e ao MOC, entidade responsável pela execução de alguns subprogramas do PETI.

Nossas pesquisas apontaram que o PETI se subdividiu em três fases. A primeira delas, considerada a mais profícua, vigorou de 1997 até 2001, período em que foi implantado o 
Programa Complementar MOC/Fundo das Nações Unidas para a Infância (UNICEF) com consentimento da COMPETI. Esse programa tinha os objetivos de qualificar as atividades do PETI e criar subprojetos voltados para: a geração de renda, com o Projeto Prosperar; a participação familiar, com o Programa Agentes de Família (PAF); e aprendizagem/leitura, com o Projeto Baú de Leituras (PBL).

A segunda tem como marco a Portaria N. 458 de 4 de outubro de 2001, que define as diretrizes e normas do PETI. Durante esse período (1997-2001), e com mais intensidade na primeira fase, o PETI era considerado pela população local como um programa atrativo e cobiçado. As crianças e os adolescentes saiam de casa cedo e voltavam no fim do dia. Nessa jornada de educação integral, em um turno frequentavam a escola regular e no outro as atividades complementares. As refeições eram servidas três vezes ao dia: almoço e lanche pela manhã e pela tarde.

Na Jornada Ampliada, cada dia da semana era mesclado com atividades diferentes: recreação, reforço escolar, jogos educativos, campeonatos de futebol, leitura, músicas, dramatizações, desenvolvimento de habilidades, festejos das datas comemorativas etc. Porém, com a defasagem do recurso de manutenção, o PETI, que era popularmente rotulado como um "programa rico e cheio de fartura”, passou a sofrer algumas restrições que comprometeram a linha de atuação adotada pela comissão municipal responsável pelo programa. Situação que se agravou anualmente com o aumento dos preços dos alimentos, material de consumo e didáticos.

As crianças e os adolescentes vivenciavam no PETI atividades de conteúdo escolar e recreativas. Os monitores destinavam cada dia da semana, conforme seu planejamento, para realizar tarefas distintas. Os educadores escolhiam, também, o dia específico para trabalhar com a leitura, embora todos os dias o reforço escolar acontecesse, porém intercalado e envolvido com jogos educativos, recreação e brincadeiras. Essa característica tornava o ambiente da UJA atrativo ao permitir divertimentos típicos da infância, o que não era comum nem em suas casas nem na escola regular. Com isso, a existência do PETI no município gerou, a princípio, certo desconforto entre alguns monitores e professores da escola regular.

Como os momentos de diversão e aprendizagem contextualizada não aconteciam normalmente na vida dos beneficiários, a maioria qualificou o PETI como um programa 
transformador e positivo. Ao questionarmos aos egressos sobre o valor do PETI em suas vidas, os relatos são unânimes em elogios e aprovação.

A terceira fase, que está em vigor, surgiu como desdobramento da Portaria n. ${ }^{\circ} 666$ de 28 de dezembro de 2005, que integrou o PETI ao PBF. Com essa resolução, o Programa se transformou de tal modo que, junto às circunstâncias anteriores, compromete sua continuidade. A dinâmica da jornada foi alterada, dentre outros aspectos, por consequência da defasagem do recurso necessário para a conservação e permanência das atividades desenvolvidas desde o início. Com isso, a proposta de educação integral se resumiu à escola regular e a meio turno de atividades complementares.

As famílias beneficiadas com o PETI, que até então recebiam a Bolsa Criança Cidadã (mais conhecida como "vale” ou “chequinho”, emitido pela coordenação e trocado no banco) e a Bolsa Família, foram identificadas pelo MDS e a duplicidade do beneficio foi “cortada”. O beneficio começou a ser repassado através de um cartão magnético diretamente do Ministério ao beneficiário. A União repassou para os municípios, entre 1997-2005, o recurso para manutenção do programa e pagamento da bolsa - após 2005, a bolsa passou ser paga com o cartão magnético.

Durante a primeira e a segunda fase, o PETI, de farto e abundante, passou a ser caracterizado pela escassez e carência. O impacto da crise foi notado pela queda na receita. Consequentemente, a comissão responsável pelo programa passou a eleger prioridades. As compras passaram a ser mais seletivas, era preciso escolher o que era fundamental: os lanches diversificados, as festividades, os passeios e os jogos educativos passaram a ser substituídos pelos produtos de primeira necessidade, como gêneros alimentícios e material de limpeza.

Cerca de dois meses após o trabalho de campo, o funcionamento das jornadas em Retirolândia foi modificada. As atividades atualmente são suspensas diariamente a partir das 10 horas da manhã e às 15 horas, pois não existe recurso suficiente para fornecer alimentação, além disso, ouvimos muitas queixas do excesso de atividades conteudistas e a redução das atividades recreativas.

Algumas mudanças foram positivas, como os trabalhos por temáticas em consonância com o contexto local, contudo, esse avanço encontra-se emperrado pela falta de recursos. Esse quadro de precariedade foi potencializado com os desdobramentos da terceira fase do PETI, 
cuja integração ao PBF visava racionalizar os gastos e ampliar o atendimento. Entretanto, mesmo diante das dificuldades, não se pode afirmar que essa junção foi de todo ruim. A situação do PETI é então sintetizada como positiva em alguns aspectos e negativa por outros pela monitora Rubenilza Gonçalves, ao afirmar:

Antes havia muita empolgação, interesse e alegria. Era muito melhor. As crianças brincavam todo dia e tinham aulas de reforço. Hoje, tem aula de reforço, mas as brincadeiras são poucas devido ao planejamento exigido. Às vezes, só tem uma aula de recreação na semana. Com tanta atividade escrita, as crianças não estão tendo o mesmo entusiasmo de antes. Outra mudança que observei foi em relação à alimentação. Está diminuído a cada ano. Antes, a alimentação era mais saudável e os alunos comiam bastante. Atualmente, devido ao pouco recurso que se tem, percebo uma reversão desse quadro. Não se tem a mesma fartura de antes. A alimentação é insuficiente. Há mudanças também relacionadas à migração do PETI para o Bolsa Família. O repasse da Bolsa sempre era feito com atraso e hoje a família recebe na data certa com o cartão que antes não possuía, porém verifica-se que houve diminuição no valor da Bolsa, que era de $\mathrm{R} \$ 45,00$, e hoje esse valor caiu para uns $\mathrm{R} \$ 20,00$, outros R\$25,00, não tem valor fixo para meu conhecimento.

Ao analisarmos a resposta dessa educadora, percebemos que as mudanças não são tão claras para algumas categorias envolvidas no programa, apesar de perceber diferenças. As transformações não param, sobretudo em relação aos recursos que diminuem continuamente, pois o mesmo está vinculado ao número de indivíduos em situação de trabalho, e, segundo a Secretaria Municipal de Assistência Social, esse número vem se reduzindo.

Ratificamos que a junção PETI/PBF ainda é muito recente e que os seus efeitos ainda estão se formando, não obstante os aspectos negativos que vem a tona. A insegurança das mudanças causadas pela integração se agravou em alguns municípios, como Quinjinge, Retirolândia e Santaluz, devido ao atraso no pagamento da Bolsa. O fato aconteceu, como mostra a reportagem "Prefeituras inadimplentes causam paralisação no PETI”, da edição n. 16 do Jornal Giramundo (2005, p. 4-5). A matéria trata da inadimplência de algumas 
prefeituras com a prestação de contas de outros programas sociais, o que implicou o bloqueio dos recursos destinados ao pagamento das bolsas.

Conforme a matéria, diante dessa situação, foi registrado casos de crianças e adolescentes que deixaram a escola e voltaram para o trabalho para ajudar os pais no complemento da renda familiar. Em Retirolândia, na época, houve protesto contra a paralisação do programa, já que cerca de 700 famílias beneficiadas ficaram sem receber.

É importante esclarecer que o Governo Federal continua repassando o recurso. A questão é que as modificações do PETI foram criando uma série de situações negativas que, após mais de uma década, passaram a ser sentidas de uma só vez. Segundo Marinaldo Maciel, então secretário de Assistência Social, “o recurso financeiro tá defasado. No início do programa, onde comprávamos um botijão de gás a $\mathrm{R} \$$ 6,00, hoje é $\mathrm{R} \$ 30,00$, e um quilo de carne que era R\$ 2,00 hoje é R\$ 9,00, com o mesmo recurso do início”.

É com esse quadro insustentável que o PETI em Retirolândia atendeu, em outubro/2008, 787 crianças e adolescentes em 20 UJAs. Foi em torno dessas UJAs que o PETI se consolidou no município, modificando a dinâmica das famílias nas quais havia crianças trabalhando. Para prosseguir a reflexão das implicações desse programa, optamos por analisá-lo em duas partes. Na primeira, mencionamos a influência dos três subprojetos: Prosperar, PAF e PBL; e na segunda, através da contribuição dos egressos, apontamos a situação atual dos primeiros beneficiários na Bahia.

\section{Geração de renda para as famílias do PETI: Projeto Prosperar}

Como já mencionamos, um dos objetivos do PETI é a promoção de programas/projetos de geração de trabalho e renda para as famílias beneficiadas. Desde 1999, o MOC, em sua área de atuação, vem trabalhando com atividades de geração de renda nos municípios contemplados com o PETI. A entidade ministrava cursos e capacitações preparando as famílias para trabalhar em diversas atividades, tais como: horticultura, cooperativismo, manejo da caatinga, silagem, fenação, beneficiamento de carnes e leite, apicultura, aproveitamento da mandioca, introdução à informática, hidroponia, energia solar, construção rural, dentre outros. 
Mas é a partir de 2001, como desdobramento do Programa Complementar MOC/UNICEF aprovado pela COMPETI, que as atividades de geração de renda são ampliadas com a criação de o Projeto Prosperar. Segundo Relatório MOC (2002), esse Projeto tinha como propósito desenvolver atividades que assegurassem promoção, racionalização e potencialização do uso das propriedades rurais com assessoramento técnico, eventos de capacitação e disponibilização de linhas de crédito.

Desse modo, segundo Relatório do MOC (2002, p. 126-127), o Projeto atingiu 3.065 famílias em 95 comunidades que foram beneficiadas com assistência técnica e cursos de capacitação. O Prosperar concedeu, de acordo com o Relatório do MOC (2002, p. 127), R\$ 2.990.144,57 em linha de crédito voltada para o desenvolvimento de atividades na propriedade e apoio a microempreendimentos agrícolas e não agrícolas.

Em Retirolândia, o Prosperar é atuante nas comunidades de Bastião, Mandápolis, Mucambo e Uberlândia. A primeira começou a se destacar a partir de 2002, quando um grupo de 5 mulheres deixou o trabalho com o sisal e passou a atuar na produção de mel, iogurte, doces e também ovinos e galináceos. Mas o destaque é a produção do Tempero Natural Prosperar e do energético Multimistura - esse último foi introduzido anteriormente pela Pastoral da Criança.

O grupo dispõe de uma casa própria, onde o tempero é processado, embalado e armazenado. A casa, construída com recursos do Projeto, da associação local, da prefeitura e da contribuição do próprio grupo, garante condições de trabalho e higiene. Atualmente, o tempero está sendo vendido nos supermercados de Retirolândia e em municípios adjacentes; além disso, o grupo vem retomando a parceira com a Cesta do Povo ${ }^{5}$ - com qual negociava até 2005.

No município de Retirolândia o Prosperar prosseguiu com ações significativas. Uma delas foi o estímulo à aquisição dos produtos da agricultura familiar pelos gestores do PETI, porém, com a concorrência do comércio local, os pequenos agricultores suspenderam a comercialização. Outra iniciativa, talvez mais exitosa, é a inserção dos jovens moradores das áreas rurais como multiplicadores da assistência técnica em suas comunidades.

\footnotetext{
${ }^{5}$ Rede de lojas criada em 1979 pelo governo do estado baiano com o objetivo de promover a oferta de produtos básicos à população de baixa renda e garantir a estabilidade nos preços dos gêneros de primeira necessidade. 
Atualmente, cinco jovens - três deles egressos do PETI - do município, estão atuando, entre os quais destacamos a jovem Jailza de Lima Oliveira, moradora da Fazenda Casa Nova, que aos 22 anos conta como sua vida foi modificada após ingressar no PETI:

Devido aos conhecimentos que adquiri no PETI, consegui minha independência. Hoje, tenho a minha autoestima elevada, aprendi a me relacionar melhor com as pessoas e valorizar os recursos naturais. E, através dos exemplos que aprendi, tenho valores e virtudes reconhecidos e faço parte dos movimentos sociais. No PETI, aprendi a fazer bordado e crochê. Faço parte de um grupo de produção, o TEAR, Tecendo Arte na Região, e faço almofada, colcha, bolsa, estola etc. O grupo tem sete integrantes, que produzem e vendem no município e até em outros estados.

\section{O Programa Agentes de Família}

Desde suas primeiras normatizações, o PETI está associado à família. O MPAS (1997, p. 910) buscou garantir essa unidade ao assegurar o "apoio psicossocial expresso em entrevistas, visitas domiciliares, grupos de escuta mútua, trocas de experiências, aconselhamento, informação, orientação e encaminhamentos” acompanhados da oferta de ações especializadas como "programa de geração de renda e empregos acoplados à oferta de capacitação profissional, atendimento à demanda de justiça com assistência advocatícia e jurídica, melhoria habitacional”.

Os Agentes de Família eram jovens lideranças que, mediante remuneração simbólica, encarregavam-se de promover o envolvimento e a participação das famílias nas atividades do PETI. A escolha dos agentes era feita pelas organizações da sociedade civil com a supervisão do MOC, que realizava uma entrevista e solicitava do candidato uma redação. Os selecionados passavam por um processo de formação, no qual eram orientados sobre como agir com as famílias. Cada um tinha uma média de 40 famílias para fazer, pelo menos, uma visita mensal, além de promover reuniões nas comunidades, visitar as UJAs, esclarecer as dúvidas dos beneficiários e estudar os temas a discutir com as famílias.

À medida que os agentes acompanhavam/orientavam as famílias sobre as atividades, ficava mais fácil identificar os problemas e modificar as estratégias, já que passavam a conhecer a 
realidade das comunidades em que atuavam. Como resultado da influência dos agentes em alguns municípios do território, os pais fiscalizavam as ações do PETI. Nos Relatórios do MOC (1999-2005), consta que os pais criaram associações e comissões, estudaram o funcionamento dos conselhos e exigiram a participação nos mesmos, frequentavam as sessões na câmara, acompanhavam a gestão dos recursos nos municípios, reclamavam e orientavam a substituição de alimentos industrializados como sucos e enlatados por produtos da agricultura familiar, entre outros.

Muitas temáticas foram discutidas com a participação dos agentes, contribuindo, muitas vezes, para o processo socioeducativo das famílias beneficiadas - a maior parte era composta por indivíduos sem escolaridade. Os documentos produzidos pelos idealizadores do PAF fazem crer que esse programa fluiu como uma das melhores propostas do PETI. Contudo, no trabalho de campo, notamos muitos entraves, como: a baixa escolaridade dos agentes, que impedia a compreensão dos temas discutidos; o pouco envolvimento das entidades da própria sociedade; a distância entre as comunidades que os agentes atuavam; e o número insuficiente de agentes para dar cobertura às comunidades distantes.

Apesar do sucesso atribuído ao PAF, é válido pontuar que se acaso todas essas ações de empoderamento e participação das famílias já aconteceram, elas deixaram de existir “como num passe de mágica” - indícios de como as relações foram firmadas num ambiente de fragilidades.

\section{O Projeto Baú de Leitura}

O Baú de Leitura é uma das atividades educativas da Jornada Ampliada. Criado em 1999, com o nome Mala de Leitura, o Baú é uma espécie de caixa confeccionada com fibras de sisal cheia de livros que se desloca entre as jornadas e as escolas regulares com o objetivo de proporcionar momentos de leitura e reflexão às crianças e adolescentes que não tinham oportunidade de fazê-lo. O PBL destina-se, em específico, aos educadores de escolas públicas, sejam da jornada regular ou da ampliada (PETI), buscando-se atingir os alunos, incentivando-os a ler mais e dar mais sentido ao próprio ato de ler, segundo Baptista et al. (2006).

O Baú é composto por obras agrupadas em três eixos norteadores ou “motes”, que orientam a escolha do seu acervo. O primeiro mote aborda questões relacionadas à identidade 
pessoal, cultural e local; o segundo, sobre a relação dos indivíduos com a natureza e ambiente; e o terceiro aborda o papel social dos leitores na família e na comunidade. Cada Baú contém 45 volumes com 15 títulos que abordam os três motes. São livros da literatura infanto-juvenil, nos quais podem ser encontradas fábulas, histórias, poemas, lendas indígenas e africanas, entre outras.

O Baú fica sob a responsabilidade do educador-leitor, porém à disposição para leitura das crianças e suas famílias, ou de outros interessados. Cada educador passa por um processo formativo que constitui uma das fases do projeto; a outra é o desenvolvimento do trabalho pedagógico, com as crianças, os adolescentes e suas famílias. O primeiro passo da proposta metodológica é a oficina de sensibilização, na qual são estimuladas situações de autoconhecimento e o educador é levado a refletir sua história pessoal e de sua comunidade. Como a proposta é processual, os educadores participam de outros encontros que ocorrem de forma semelhante a anterior; são as oficinas de retomada do processo, avaliação e planejamento.

Existem ainda, como expõem Souza et al. (2006, p. 79-86), outras atividades que aprimoram o processo formativo, como: a apresentação do PBL; a trocas dos Baús entre os educadores (acontece depois que todos os livros são trabalhados; no geral, procura-se nesses momentos incentivar a mística e a socialização da aprendizagem); visitas técnicas de monitoramento (feitas pelos técnicos de educação do MOC); encontros de coordenadores (momento de troca de experiências entre os representantes do projeto de cada município); núcleo de estudo; encontros de avaliação e planejamento (momentos de socialização entre os educadores e o coordenador do projeto em cada município); e intercâmbios (são as trocas de experiências através de encontros regionais e estaduais).

Quando o PBL começou, em 1999, atingia 675 crianças e adolescentes em 3 municípios. Em 2007, passou a atuar em 52 municípios do estado, envolvendo 28.539 crianças e adolescentes acompanhados por 1.004 educadores em torno de 942 Baús. No Território do Sisal, em 2007, o PBL esteve presente em 19 dos seus 20 municípios, envolvendo 13.535 crianças/adolescentes acompanhados por 478 educadores.

Segundo Hitti e Souza (2006, p. 137-139), desde 2004 a equipe de Educação do MOC vem efetuando um diagnóstico do PBL. Essa sistematização identifica quantitativamente alguns indicadores qualitativos do projeto. Dentre as informações são registrados o número de 
crianças e educadores que estão lendo, tanto as obras do acervo como outras; o número de contos, poesias, histórias, paródias, músicas, jornais e murais produzidos por crianças e educadores; identifica a participação de familiares que estão tendo acesso aos livros do Baú; identifica-se igualmente se crianças e educadores se apresentam na comunidade, na câmara de vereadores, nos conselhos ou em outros municípios.

Nos trabalhos de campo em Retirolândia, observamos que as atividades socioeducativas do PETI são precárias. Faltam a formação continuada dos professores e uma infraestrutura que viabilize o desenvolvimento das ações educativas, como salas adequadas, luz elétrica, quadras de esporte, salas de informática, dentre outros.

Mesmo com tanto entraves, o PBL se consolidou em muitas comunidades como um sucesso, já que é a única atividade com êxito. Um dos principais momentos do PBL é o chamado evento de devolução, no qual a comunidade se reúne para assistir à apresentação das obras de formas diversas, como dramatizações, danças, paródias, e ouvir as histórias dos livros lidos pelas crianças e adolescentes.

Outro momento de igual relevância é a troca do Baú. Como já afirmamos, ele é itinerante. Depois de explorados todos os livros com as crianças e adolescentes, ou mesmo adultos, o monitor troca de Baú com outro educador do mesmo município. No geral, essa etapa é festejada, caracterizando-se como uma oportunidade para os alunos-leitores exporem as histórias lidas.

Essa prática, na Jornada Ampliada da comunidade de Lagoa Grande, no município de Retirolândia, se consolidou como um motivo de festa e mudou a dinâmica da jornada. Durante uma visita à comunidade, conhecemos alguns membros da União da Juventude Popular (UJP), grupo “nascido” como desdobramento das atividades de troca do Baú e que atua em apresentações musicais e danças.

Um dos idealizadores do grupo foi o próprio monitor que atua na comunidade e que começou a estimular a criatividade de jovens artistas durante a atividade de troca de Baú. Essa prática, que em outras UJAs acontece sem muito envolvimento dos integrantes do Programa, deu dinamicidade à unidade de Lagoa Grande, levando-a a ser conhecida popularmente como sede da “jornada modelo”. Segundo os integrantes da UJP, a mesma garotada que bagunçava; “jogava comida dentro do filtro” e "atirava um ao outro contra as cercas” que separa a UJA das demais propriedades, passou da condição de desacreditada a 
referência. O grupo, formado por egressos e atuais beneficiários, hoje se apresenta em diversos eventos dentro e fora do estado.

Além disso, na mesma UJA foi adotado o projeto horta ecológica, com a qual as crianças/adolescentes aprendem a conviver com o semiárido, conhecendo tecnologias alternativas, não poluentes e acessíveis, produzindo coletivamente alimentos orgânicos. Ao visitarmos a UJA de Lagoa Grande, observamos que a horta está desativada por falta de apoio e de recursos, mas o monitor e as crianças continuam cuidando do pomar com árvores frutíferas como (acerolas, pinhas e caju).

Retomando o PBL, ratificamos sua importância ao percebemos como o projeto é enaltecido pelos atuais e ex-beneficiários, o que se confirmou nas entrevistas com os egressos e nos grupos focais, como demonstra a egressa Geovane dos Santos, 17 anos, estudante do Colégio Estadual Olavo Alves Pinto:

O Baú de Leitura incentiva muito as crianças a ler. Eu, por exemplo, tomei muito gosto pela leitura através do Baú, pois nele vinham incluídos muitos livros interessantes; já cheguei a ler até 30 livros no ano. Mas a criança tem o dever de ir para a escola e para o PETI, porque corre o risco de perder o beneficio. Com o Baú de Leitura, nós aprendemos a fazer peças teatrais e acostumamos com o público, como em meu povoado (Vista Bela), por exemplo: nós formamos um grupo teatral, com pessoas que já saíram do PETI, que já completaram a idade e com pessoas que ainda estão no PETI, pessoas que já são mães, que ainda gostam e vivem o que aprenderam no PETI.

Ou através da garota Suelen Santos Almeida:

O Baú é muito importante. Ele me ensinou várias coisas e ajuda também. Me ajudou principalmente a aprender a ler, a desenvolver criatividade etc. Às vezes, os professores ensinavam como é bom fazer criatividades na sala de aula e em grupo. A partir disso, eles desenvolvem o Baú de Leitura com a gente. O Baú é a coisa principal do PETI. Ele é feito de sisal, contém folhas de oficio, lápis, classificador e principalmente livros para o aprendizado do aluno. Mas às vezes é ruim, porque que nem todos os alunos sabem ler. 
Analisando a resposta de Suelen, observamos um dos entraves do PBL. O fato é que mesmo as atividades do Baú, tão exaltadas, precisam ser mais bem analisadas. O educador só troca o Baú quando todos os livros forem lidos por todas as crianças. Como a maior parte das turmas do PETI é formada por crianças e adolescentes com idades e séries distintas (multisseriadas), alguns alunos sabem ler e outros não, situação que emperra o processo.

Outro grave problema é a atual crise porque o PETI está passando e que afeta a dinâmica do PBL. Como as aulas são suspensas na metade da manhã ou da tarde, os educadores não fazem o trabalho com qualidade. Além disso, como a frequência está muito irregular (uma semana a criança participa das atividades, na outra falta e na seguinte frequenta novamente) a criança fica “atrasada” em relação às demais e os monitores precisam retornar aos livros não lidos para que ela acompanhe.

Mesmo esse projeto, que congrega os resquícios positivos do PETI, está ameaçado devido a instabilidade da situação contratual dos monitores. Na Bahia, a contratação dos monitores, desde o início do Programa, foi confrontada com várias questões legais. Os estados e as prefeituras não podiam fazê-lo, uma vez que os educadores não foram selecionados por concurso público, mas por processo seletivo com prova escrita e entrevista.

Sempre que o impasse da situação trabalhista emergia, uma solução temporária era tomada. Em janeiro de 2009, o contrato termina e o governo do estado, através da Secretaria de Desenvolvimento Social e Combate à Fome (SEDES), pretende transferir a responsabilidade da gestão dessa política pública para entidades da sociedade civil. A proposta, firmada no "Edital de Chamamento Público de Entidades - PETI" vigente até o fim de outubro/2008, pretendia selecionar as entidades interessadas em apoiar os municípios na operacionalização de enfrentamento ao trabalho infantil e na execução de ações socioeducativas.

\section{Identificando os egressos}

Nesta seção, pretendemos verificar, com base nas respostas dos egressos, se os objetivos do PETI, mencionados anteriormente, foram exitosos. Para tanto, consideramos necessário o conhecimento das principais características dos 99 egressos que responderam o questionário. Dos entrevistados 51,5\% pertence ao sexo masculino e $48,5 \%$ ao sexo 
feminino, proporção semelhante à Pesquisa Criança Cidadã efetuada em 1997. Em relação à idade, 41,1\%, se concentra na faixa entre 17 a 19 anos, seguidos da faixa de 22 a 24 anos, com $30,3 \%$, e 20 a 21 , com $14,1 \%$.

Entre os egressos entrevistados, podemos afirmar que o objetivo do PETI, de retirar crianças e adolescentes do trabalho perigoso, penoso, insalubre e degradante, não se concretizou totalmente. Essa assertiva se baseia nas respostas obtidas, nas quais 25,3\% afirmaram trabalhar enquanto estavam no Programa, apesar de saber que era proibido. Porém, mesmo entre alguns egressos que confessaram trabalhar e receber a bolsa, é perceptível a conscientização de que o trabalho infanto-juvenil penoso não deve existir. Adeládio Oliveira Santana Filho, 22 anos, e Rizélia Bispo dos Santos, 24 anos, egressos que mesmo no PETI permaneceram no trabalho, confirmam esses aspectos. Para Adeládio, “o trabalho infantil não deveria acontecer, mas há muitas famílias pobres que precisam e não tem outra opção”. Rizélia afirma: “o trabalho infantil é uma crueldade, mas é uma maneira que as crianças procuram para ajudar suas famílias”.

É importante mencionar que essa visão não foi unânime, apesar dos diversos momentos de sensibilização e discussão sobre erradicação do trabalho infantil, seja nas jornadas ou nas reuniões com os pais. A cultura do trabalho durante a infância como uma situação "natural” foi identificado entre $16,2 \%$ dos egressos, para os quais o trabalho durante a infância não prejudica o desempenho na escola.

A longo prazo, o objetivo também não foi alcançado. É comum encontrarmos crianças e adolescentes trabalhando na feira-livre durante os sábados. Na pesquisa de campo, identificamos que a maioria dessas crianças não trabalha para ajudar no sustento doméstico. Num bate-papo informal, notamos que a maioria delas passa o dia carregando feira nos "carrinhos de mão" e no fim do dia usam o dinheiro recebido para brincar nas casas de jogos eletrônicos ou acessar a internet.

Encontramos casos em que os beneficiários abandonaram o programa e retornaram ao trabalho, como fez o adolescente Robeilton da Silva Oliveira, de 14 anos, morador do povoado de Jitaí, em Retirolândia. O garoto integrava o PETI, mas resolveu deixá-lo em meados de 2008, pois, segundo ele, “trabalhando com o sisal dá pra receber por semana R\$ 15,00, R\$ 30,00, e pra receber o dinheiro do PETI eu tenho que esperar um mês”. A rotina 
de Robeilton é trabalhar no sisal pela manhã, ir para escola à tarde e fazer suas atividades escolares à noite.

Em relação ao objetivo de possibilitar o acesso, a permanência e o bom desempenho de crianças e adolescentes na escola, afirmamos que os dois primeiros não foram comprometidos, haja visto que 58,6\% concluíram ou estão prestes a concluir o ensino médio, 26,3\% estão concluindo o ensino fundamental e 10,1\% já concluíram esse último. Porém, em relação ao desempenho, não pareceu que o objetivo foi atingido, se bem que não é um aspecto fácil de ser analisado.

Identificamos que muitos egressos não conseguiam interpretar as questões propostas. Notamos, por exemplo, que no item em que questionávamos a faixa etária e o nível de escolaridade, alguns responderam em duplicidade, e o mesmo se repetia em outras perguntas do questionário. Outros até afirmaram não ter condições de responder e que precisariam da ajuda de terceiros, pois não entendiam o que era solicitado. Registramos que averiguar o desempenho na escola seria mais bem deslindado caso comparássemos os indicadores de aprovação, conservação e desistência na escola regular antes e após o programa. Até iniciamos essa averiguação ao fazermos o levantamento do total de alunos e dos indicadores citados em 1997 e 2007, mas com as dificuldades, como as atas pouco claras e o tempo restrito, optamos por continuá-la em outro momento.

O desempenho desses indivíduos na escola esteve comprometido desde cedo. Ramos e Almeida (1997) já haviam demonstrado essa realidade ao apontar, na Pesquisa Criança Cidadã, que 77,9\% das crianças começaram a trabalhar entre os 3 e os 9 anos, conjugando, simultaneamente, trabalho e escola. Ratificamos essa situação ao apontarmos que entre os entrevistados 51,5\% começaram a trabalhar antes dos 10 anos de idade.

Durante as duas primeiras fases do PETI, reconhecemos que o programa cumpriu o objetivo de incentivar e fomentar a ampliação de conhecimentos da criança e do adolescente, por meio de atividades culturais, esportivas, artísticas e de lazer no período complementar ao da escola, o que se confirma com as respostas.

Propusemos que os egressos indicassem o motivo que os fazia frequentar a jornada. As respostas confirmaram nossa hipótese de que a Bolsa Criança Cidadã era o principal motivo, mas surgiram outros elementos, como o Baú de Leitura, que atraíam a frequência das crianças e adolescentes. A multiplicidade de atividades do PETI é sintetizada pela 
egressa Jaciara de Almeida, 23 anos, para quem o Programa “oferecia tempo para estudar, reforço escolar, lazer, oportunidade de aprender atividades artísticas e ajuda financeira”; ou Renilton Silva, 22 anos, ao afirmar que “o PETI é um programa onde as crianças tinham o lazer para brincar e responder as suas atividades escolares; lá tinha também o Baú de Leitura, onde a gente fazia grandes apresentações muito engraçadas”.

Em relação ao apoio e a orientação às famílias por meio da oferta de ações socioeducativas percebemos que houve avanço nos primeiros anos de existência do PETI, porém não se consolidaram. Um dos frutos dessa ação é o engajamento político de alguns egressos, desdobramento das ações socioeducativas ministradas tanto nas jornadas quanto nos encontros com as famílias que participavam das atividades propostas pelo antigo PAF, como os dias de estudo, palestras, visitas e esclarecimentos. Desse modo, 60,6\% dos egressos participam atualmente de alguma organização, seja associação, partido político, cooperativa, sindicato, grupo de igreja ou coletivo de jovens.

Em se tratando do objetivo de implantar projetos de geração de renda, identificamos que eles existiram, mas é necessário uma articulação ainda mais forte das diversas instâncias do governo no sentido de facilitar a atuação dos grupos. Durante os trabalhos de campo, mantivemos contato com grupos de mulheres artesãs, costureiras, cozinheiras, com jovens contratados para atuar nos movimentos sociais, mas as iniciativas ainda são limitadas. Outra situação é que não percebemos uma significativa ascensão intergeracional em relação aos egressos e seus pais. A maior parte dos pais trabalha na roça, sobretudo com o sisal.

Ao questionarmos a atual ocupação dos egressos, observamos que 30,4\% estão desempregados, 29,3\% apenas estudando e 18,2\% retornaram ao trabalho na roça com o sisal, (re)vivendo a rotina ao lado dos seus pais. Por outro lado, parte dos egressos não foi encontrada. Como já mencionamos, 81 deles migraram, parte desses ex-beneficiários permaneceu no estado e até mesmo em municípios próximos a Retirolândia. De acordo com os familiares e amigos mais próximos desses egressos, 85,2\% migraram para outros locais em busca de oportunidade de trabalho, 8,7\% foram morar em assentamentos rurais e sobre os demais não obtivemos informações.

Dentro do próprio estado, a maior concentração dos egressos está em Salvador, posicionado como a primeira opção (35,8\%), seguido por Conceição do Coité (9,9\%), Nova Palmares $(8,7 \%)$ e Valente $(7,4 \%)$. Fora do estado, a maior concentração é encontrada em São Paulo 
(12,3\%), Goiás (4,9\%) e Minas Gerais (4,9\%). Esses números evidenciam que um dos objetivos do PETI, promover e implementar programas de geração de renda, não atendeu as expectativas.

Os resultados da nossa pesquisa apontam que o PETI gerou implicações de ordens distintas e seu sucesso só seria plenamente realizável se conectado a outros programas complementares, capazes de propiciar aos egressos empregos e renda às famílias. Entendemos que o Projeto Prosperar e o Programa Agentes de Família se constituíram em tentativas com tais finalidades, entretanto, elas não tiveram o alcance desejado e foram incapazes de superar os impasses e descontinuidades dos programas governamentais como comumente acontecem.

\section{Considerações finais}

A situação do trabalho infantil passou a ser uma prática combatida com ênfase nas duas últimas décadas do século XX. O motivo dessa mudança de padrões sociais, instituídos secularmente, foi a criação de mecanismos de coerção estruturados por uma rede em defesa dos direitos do público infanto-juvenil, articulada por organismos internacionais, Estado e sociedade civil.

Pode-se dizer que a rede de proteção à criança pressionou para que as leis fossem cumpridas corretamente, tendo em vista que a primeira legislação que regulava o trabalho infantil foi oficializada durante a Primeira República. Como uma das medidas consoante os “novos” valores sociais, o Governo Federal criou, em 1996, o PETI, que buscava congregar o acesso à educação e a proibição do trabalho infantil - dois grandes referenciais que expressam as concepções de defesa e proteção às crianças e aos adolescentes.

Como foi abordado, o PETI se dividiu em três fases. Cada período trouxe implicações de natureza positiva ao tempo em que evidenciava suas limitações. Desde a segunda fase, os aspectos restritivos se tornaram mais perceptíveis, acentuando-se a partir de 2006 com a integração ao PBF. A defasagem dos recursos se tornou o principal impasse. O descompasso entre o valor recebido por cada criança/adolescente e o preço da alimentação e materiais de consumo ficou tão acentuado que a solução encontrada foi a suspensão das aulas nas jornadas na metade do turno para evitar as despesas com o lanche e o almoço. 
O trabalho de campo indica que na primeira fase os resultados do programa foram considerados positivos, não obstante as dificuldades enfrentadas para dirimir os ranços do clientelismo assistencialista - no momento da seleção das famílias, por exemplo, algumas entidades já possuíam listas prontas com os nomes de supostas famílias carentes, conforme salientado. Outro percalço foi o processo de participação social, necessário à gestão dos programas sociais pós-Constituição de 1988, visto com receio pelas lideranças políticas locais temerosas da perda de poder e prestígio. Nas fases subsequentes, essas dificuldades se somaram à defasagem dos recursos.

Ao focarmos nossa atenção nos objetivos do PETI, observamos que cada um deles contou com a criação de um subprograma específico. Trata-se do Programa Complementar MOC/UNICEF, que, centrado na retirada das crianças e adolescentes do trabalho e no ingresso à escola/jornada, criou ações de geração de emprego e renda (Programa Prosperar); atividades socioeducativas para as famílias (Programa Agentes de Família); e o fomento às práticas culturais e artísticas (Projeto Baú de Leitura).

O Programa Prosperar, desde que foi criado, desenvolve propostas de geração de renda às famílias, como subsídios à criação de microempreendimentos, cursos de capacitação e o apoio à comercialização dos produtos entre os agricultores familiares e o grupo gestor mesmo antes da diminuição dos recursos do PETI, essa transação já vinha decaindo por causa da concorrência com os comerciantes locais.

O PAF desenvolvia ações socioeducativas com as famílias do PETI, como debates e dias de estudo. Essas propostas mudaram aspectos do cotidiano, para além dos beneficiários, ao favorecer a participação social, elevar a autoestima das mulheres e valorizar a "identidade sertaneja”. Como consequência, a família se envolvia, participava e opinava nas atividades do PETI. Nos últimos anos, a participação da família não tem se mostrado com muito vigor, pois diante dos impasses manifestados, não há informações de que existam mobilizações no sentido de reverter o quadro que se apresenta para o futuro.

O PBL congrega toda estima e repercussão construtiva por parte da comunidade, dos que estão no PETI e dos egressos. Como as atividades socioeducativas do PETI estão precárias, o PBL se consolidou em muitas comunidades como um sucesso. Contudo, os desdobramentos da crise que afetam o PETI repercutem na dinâmica do Baú. A redução do horário da jornada dificulta a realização da atividade que é organizada semanalmente pelos 
educadores com base na leitura e apresentação das obras. A presença de crianças e adolescentes que não sabem ler também emperra o processo, uma vez que a maioria é oriunda de turmas multisseriadas, sendo a aprendizagem diferenciada. Como a maior parte das jornadas também reúne alunos de idade e série distintas, o problema permanece.

O discurso dos grupos envolvidos no PETI é unânime em afirmar que as ações socioeducativas desse programa permitiram o acesso à educação, o bom desempenho na escola e a diminuição da evasão. Ao questionarmos a existência de estudos confirmando esses indicadores, não obtivemos nada de concreto. Os coordenadores de monitores apontam que todos os anos, geralmente no mês de novembro, solicitam aos monitores a previsão de aprovação e conservação (repetência) das crianças e adolescentes na escola regular. Os dados são encaminhados à equipe de educação do MOC e o município não possui arquivo próprio. Solicitamos essas informações à referida entidade e não obtivemos respostas em tempo hábil.

Por outro lado, muitos aspectos ainda não são possíveis de mensurar. A situação de grande parte dos egressos que migraram em busca de trabalho é uma delas. Foram muitas as reclamações da inexistência de atividades profissionalizantes ou semiprofissionalizantes no programa, o que seria a solução para os filhos das famílias menos abastadas.

O funcionamento e a gestão das UJAs também são questões a ser pensadas. Desde o início do programa, a falta de transporte impedia que os coordenadores visitassem as diversas UJAs espalhadas pelo município para fiscalizar e resolver impasses. A escassez de água também foi um problema recorrente, e por diversas vezes era o motivo para a suspensão das aulas. A infraestrutura das jornadas, apesar da construção de cinco UJAs e as adaptações feitas nas demais, também não está em conformidade com as propostas do programa. Nem todos os espaços possuem energia elétrica (o que impede o uso de geladeira para armazenar os alimentos, impossibilitando ainda o uso de som e televisão), os ambientes não são bem iluminados e ventilados, falta área para recreação e estudo.

O planejamento pedagógico adotado atualmente favorece a participação dos monitores ao permitir que opinem na escolha das temáticas abordadas nas aulas. Mas a defasagem dos recursos e a carência de materiais para dinamizar as atividades socioeducativas tornam as aulas muito conteudistas, e cada dia mais semelhantes à escola regular. A falta de conexão entre os professores da rede e os monitores também deve ser revista - o trabalho conjunto 
ocorre uma vez no ano durante a “semana pedagógica” municipal. A instabilidade da situação contratual dos educadores contribui para a perda de estímulo. O contrato finaliza no início de 2009 e metade dos educadores de Retirolândia estão com os empregos ameaçados.

Apesar de todos os impasses, apontamos que a criação do PETI é vista como salutar, especialmente para o Território do Sisal. A proposta de educação integral, com acesso à leitura, atividades artísticas e esportivas, alimentação, fardamento, alternativas de geração de renda, a valorização da cultura local, a organização das famílias e dos egressos e o auxílio financeiro foram, para muitos beneficiários, uma novidade e exemplo de cidadania.

\section{Referências}

ANTUNIASSI, M. H. R. Trabalhador infantil e escolarização no meio rural. Rio de Janeiro: Zahar, 1983.

ARAÚJO, T. B. Ensaios sobre o desenvolvimento brasileiro: heranças e urgências. Rio de Janeiro: REVAN/FASE, 2000.

ARIÈS, P. História social da criança e da família. Tradução de Dora Flaksman. 2. ed. Rio de Janeiro: Guanabara Koogan, 1981.

ARRETCHE, M. T. S. Estado federativo e políticas sociais: determinantes da descentralização. Rio de Janeiro: REVAN; São Paulo: FAPESP, 2000.

ARRETCHE, M. T. S. Tendências no estudo sobre avaliação. In: RICO, E. M. (Org.) Avaliação de políticas sociais: uma questão em debate. 4. ed. São Paulo: Cortez/Institutos de Estudos Especiais, 2006. p. 29-39.

ATLAS Desenvolvimento Humano no Brasil, 2003. Disponível em: http://www.pnud.org.br/atlas/instalacao/index.php. Acesso em: 31.01.2008.

BADINTER, E. Um amor conquistado: o mito do amor materno. Tradução de Waltensir Dutra. 8. ed. Rio de Janeiro: Nova Fronteira, 1985.

BAPTISTA, F. M. C.; ALVES, J. N.; BAPTISTA, N. Q. (Orgs.) Projeto Baú de Leituras. Feira de Santana: MOC, 2006. 
BRASIL. Estatuto da criança e do adolescente (1990). Estatuto da criança e do adolescente/ trabalho de pesquisa e elaboração de índice por Maria Celeste José Ribeiro. 4. rd. Revisada e atualizada. Brasília: Senado Federal, Subsecretaria de Edições Técnicas, 2003.

ENGUITA, M. F. A face oculta da escola: educação e trabalho no capitalismo. Tradução de Tomaz Tadeu da Silva. Porto Alegre: Artes Médicas, 1989.

GERARDI, L. H. O.; SILVA, B.-C. M. N. Quantificação em geografia. São Paulo: Difel, 1981.

GOMES, A. A. Apontamentos sobre a pesquisa em educação: usos e possibilidades do grupo focal. Eccos Revista Cientifica, v. 7, n. 2. p. 275-290, 2005. Disponível em:

http://redalyc.uaemex.mx/redalyc/pdf/715/71570203.pdf. Acesso em: 05.06.2008.

HITTI, S. M. G.; SOUZA, Z. L. Experiência do MOC (BA) com o Baú de Leitura. In: BAPTISTA, F. M. C.; BAPTISTA, N. Q. (Orgs.) Baú de leituras: lendo histórias, construindo cidadania. João Pessoa: PB, 2006. p. 130-144.

JORNAL GIRAMUNDO. Feira de Santana: Movimento de Organização Comunitária, 2003-2007.

LAMÊGO, S. A implantação da Jornada Ampliada na Região Sisaleira da Bahia: estratégia de manutenção da criança na escola (registro de experiência). Salvador: MOC, Projeto Axé, 1999.

LEAL, M. G. A. A arte de ter um ofício: Liceu de Artes e Ofícios da Bahia (1872-1996). Salvador: Fundação Odebrecht/Liceu de Artes e Ofícios da Bahia, 1996.

LIMA, A. S. Sertão, sisal, suor: os prazeres e pesares dos trabalhadores do sisal em Retirolândia-BA. Santo Antonio de Jesus: UNEB, 2006.

LOURENÇO, M. S. Políticas públicas e desenvolvimento. In: SILVA, C. L.; MENEZES, J. T. G. (Orgs.) Reflexões sobre o desenvolvimento sustentável: agentes e interações sobre a ótica multidisciplinar. Petrópolis: Vozes, 2005. p. 41-58.

MINISTÉRIO da Previdência e Assistência Social. PETI: manual de orientações. Brasília: MPAS, 2002. 
MINISTÉRIO da Previdência e Assistência Social. PETI: área de assistência social. Brasília: SAS, [199-]. (Série Programas de Assistência Social)

MINISTÉRIO da Previdência e Assistência Social. Diretrizes e normas para implementação do PETI: versão preliminar. Brasília: MPAS/ SAS, 1997. (Programa Brasil Criança Cidadã)

MINISTÉRIO do Desenvolvimento Social e Combate à Fome. Análise situacional do PETI. Brasília: MDS, 2004a. Disponível em: http://www.mds.gov.br/programas/redesuas/protecao-social-especial/programa-de-erradicacao-do-trabalho-infantilpeti/relatoriofin. Acesso em: 14.02.2008.

MINISTÉRIO do Desenvolvimento Social e Combate à Fome. Política nacional de assistência social. Brasília: MDS/SNAS, 2004b. Disponível em:

www.mds.gov.br/concursos/pss-2008/pnas_final.pdf . Acesso em: 05.11.2008.

MINISTÉRIO do Desenvolvimento Social e Combate à Fome. Programa de erradicação do trabalho infantil: cartilha do PETI. Brasília: MDS, 2004c. Disponível em:

www.mds.gov.br/programas/rede-suas/protecao-social-

especial/servicose.../rede...peti/...peti.../view. Acesso em: 05.11.2008.

ORGANIZAÇÃO Internacional do Trabalho. O fim do trabalho infantil: um objetivo ao nosso alcance. Relatório global no quadro do seguimento da declaração da OIT sobre os princípios e diretrizes fundamentais no trabalho. Brasília, 2006.

ORGANIZAÇÃO Internacional do Trabalho. O trabalho infantil: pela abolição do trabalho infantil. Brasília: OIT, 1993.

PASSETTI, E. Crianças carentes e políticas públicas. In: DEL PRIORE, M. (Org.) História das crianças no Brasil. 3. ed. São Paulo: Contexto, 2002. p. 347-375.

POSTMAN, N. O desaparecimento da infância. Tradução de Suzana Menescal de Alencar Carvalho e José Laurentino de Melo. Rio de Janeiro: Graphia, 1999.

RAMOS, A. R. N.; ALMEIDA, F. M. B. G. (Coords.) Cadastro de famílias a serem beneficiárias do PETI na área rural da Região Sisaleira do estado da Bahia. Criança Cidadã. Salvador: UFBA/SETRAS/CRH, 1997. (Relatório Final Município de Retirolândia e Santaluz) 
RAMOS, A. R.; NASCIMENTO, A. D. Resgatando a infância: a trajetória do PETI na Bahia. Salvador: MOC/OIT/Unicef, 2001.

RELATÓRIO Anual de Atividades do MOC. Feira de Santana: Movimento de Organização Comunitária, 1995-2007.

RIZZINI, I. Pequenos trabalhadores do Brasil. In: DEL PRIORE, M. (Org.) História das crianças no Brasil. 3. ed. São Paulo: Contexto, 2002. p. 376-406.

SILVEIRA, C.; BOCAYUVA, C.; ZAPATA, T. Ações integradas e desenvolvimento local: tendências, oportunidades e caminhos. In: BAVA, S. C.; PAULICS, V.; SPINK, P. (Orgs.) Novos contornos da gestão local: conceitos em construção. São Paulo: Programa Gestão Pública e Cidadania/FGV-EAESP, 2002. p. 245-270.

SINDICATO dos Trabalhadores Rurais de Retirolânida. Bode escola: alternativa de geração de renda no sertão. Retirolândia: STR, 2001.

SOUZA, J. F.; SOUZA, A. L. F. Crianças e adolescentes: futuro da região sisaleira? (avaliação PETI-BAHIA). Feira de Santana: MOC/UNICEF, 2003.

SOUZA, M. I. S.; SANTOS, M. S. R.; BAPTISTA, N. Q.; PEIXOTO, S. S. F. Processo de formação de educadores-leitores. In: BAPTISTA, F. M. C.; BAPTISTA, N. Q. (Orgs.) Baú de leituras: lendo histórias, construindo cidadania. João Pessoa: PB, 2006. p. 65-86.

THOMPSON, E. P. A formação da classe operaria inglesa II: a maldição de Adão. Tradução de Renato Busatto Neto e Cláudia Rocha de Almeida. 3. ed. São Paulo: Paz e Terra, 1987.

Anexo 1 - Lista de Siglas

\begin{tabular}{|l|l|}
\hline Cad-Único & Cadastro Único para Programas Sociais para o Governo Federal \\
\hline COMPETI & Comissão Estadual de Prevenção e Erradicação do Trabalho Infantil \\
\hline CRH-UFBA & Centro de Recursos Humanos da Universidade Federal da Bahia \\
\hline ECA & Estatuto da Criança e do Adolescente \\
\hline MDA & Ministério do Desenvolvimento Agrário \\
\hline MOC & Movimento de Organização Comunitária \\
\hline MPAS & Ministério da Previdência e Assistência Social \\
\hline MTE & Ministério do Trabalho e Emprego \\
\hline OIT & Organização Internacional do Trabalho \\
\hline PAF & Programa Agentes de Família \\
\hline PBL & Projeto Baú de Leitura \\
\hline PBF & Programa Bolsa Família \\
\hline PETI & Programa de Erradicação do Trabalho Infantil \\
\hline SAS & Secretaria de Assistência Social \\
\hline
\end{tabular}




\begin{tabular}{|l|l|}
\hline SETRAS & Secretaria do Trabalho e Ação Social \\
\hline STR & Sindicato dos Trabalhadores Rurais \\
\hline UJP & União da Juventude Popular \\
\hline UNICEF & Fundo das Nações Unidas para a Infância \\
\hline
\end{tabular}

Artigo recebido em 11/09/2009. Aprovado em 09/10/2009 